\title{
Pengaruh Sosialisasi Perpajakan, Pengetahuan Perpajakan, Kualitas Pelayanan Fiskus dan Minat Penerapan E-Filling pada Kepatuhan WPOP
}

\author{
Putu Eka Mas Pratiwi ${ }^{1}$ \\ Fakultas Ekonomi dan Bisnis \\ Universitas Udayana, Indonesia \\ Email: ekamaspratiwi24@gmail.com
}

\author{
I Ketut Jati ${ }^{2}$ \\ Fakultas Ekonomi dan Bisnis \\ Universitas Udayana, Indonesia
}

\begin{abstract}
ABSTRAK
Tujuan dari penelitian ini untuk mengetahui sosialisasi perpajakan, pengetahuan perpajakan, kualitas pelayanan fiskus, dan minat penerapan E-Filling berpengaruh dalam meningkatnya kepatuhan pelaporan WPOP di KPP Pratama Badung Selatan. Populasi yang digunakan pada penelitian ini yaitu seluruh WPOP yang efektif terdaftar di KPP Pratama Badung Selatan dengan jumlah sampel sebanyak 100 responden dari 45.326 populasi WPOP yang masih efektif di KPP Pratama Badung Selatan pada tahun 2018 dengan teknik analisis regresi linier berganda Penelitian menggunakan kuesioner. Sampel yang digunakan adalah teknik incidental sampling ditentukan dengan rumus Slovin. Berdasarkan hasil penelitian ini ditemukan bahwa sosialisasi perpajakan, pengetahuan perpajakan, kualitas pelayanan fiskus, dan minat penerapan E-Filling menyebabkan pengaruh positif pada kepatuhan pelaporan WPOP di KPP Pratama Badung Selatan.
\end{abstract}

Kata Kunci: Sosialisasi Perpajakan; Pengetahuan Perpajakan; Kualitas Pelayanan Fiskus; Minat Penerapan EFilling; Kepatuhan Wajib Pajak.

\section{Effects of Socialization, Knowledge, Service Quality, and} Behavioral Intention Using E-Filing to WPOP Compliance

\section{ABSTRACT}

The purpose of this research is to find out the effect of socialization taxation, taxation knowledge, service quality, and behavioral intention of using E-Filing at the South Badung Pratama Tax Office. The population in this research were all taxpayers registered at the KPP South Badung. There were 100 respondents used as a sample in this research from 45.326 people who were still effective at the South Badung Pratama Tax Officer. This research instrument uses a questionary method and for data analysis techniques are used multiple linear regression analysis. The Slovin formula with an incidental sampling technique was used to calculate the sample. The results of the research show that socialization taxation, taxation knowledge, service quality, and behavioral intention of using E-Filing are positive for the individual taxpayer tax rate.

Keywords: Socialization; Knowledge; Service Quality; E-Filling, Taxpayer Compliance.

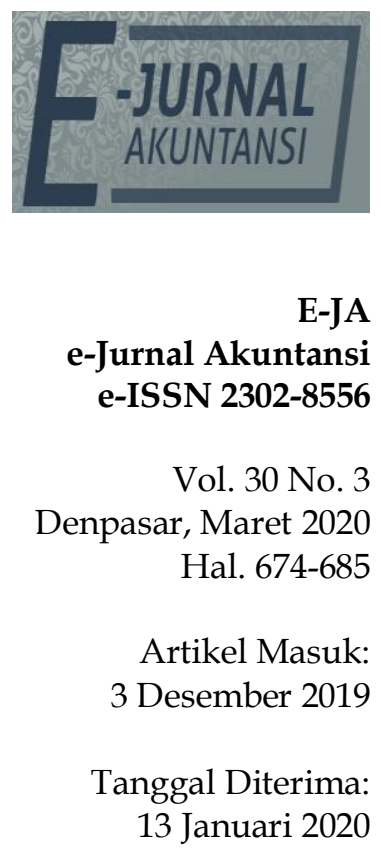




\section{PENDAHULUAN}

Suatu bangsa akan beroperasi dengan maksimal apabila sumber keuangan negara kuat dan stabil (Dessy, Windarti, \& Nourwahida, 2017). Diperlukan dana yang cukup banyak untuk pembangunan nasional yang menyebabkan pendapatan negara harus ditingkatkan (Sentanu \& Setiawan, 2016). Penerimaan pajak adalah sumber pendapatan utama bagi pemerintah di negara maju ataupun negara berkembang (Kamleitner, Korunka, \& Kirchler, 2012). Penerimaan pajak pada tahun 2014 sampai dengan tahun 2018 cenderung mengalami peningkatan. Suatu peristiwa dapat ditunjukan apabila pajak digunakan sebagai penerimaan penting bagi suatu negara berkembang ataupun negara maju untuk tujuan pembangunan nasional (Alabede, Bt. Zainol Ariffin, \& Idris, 2011). Salah satu perhatian utama pemerintah manapun adalah memungut pajak dengan benar (Hammouri \& Abu-Shanab, 2017).

Kepatuhan merupakan hal yang paling netral menjelaskan kemauan membayar kewajiban perpajakan (Kamleitner et al., 2012). Apabila kepatuhan wajib pajak akan meningkatkan karena pengetahuan perpajakan (Kasipillai \& Jabbar, 2006). Wajib pajak memiliki pengetahuan yang berpengaruh positif terhadap kepatuhan perpajakan (Santoso, 2015). Pengetahuan pajak berpacu pada suatu proses, dimana pembayar pajak menjadi sadar akan undang-undang pajak dan informasi terkait pajak lainnya (Hasseldine, 2014). Persepsi yang berkaitan tidak langsung dengan objek yang diterima oleh indera manusia untuk menyimpulkan objek yang diterima agar objek menjadi berarti (Gregory, 1997). Menurut (Mahardika, 2015) semakin meningkatnya kualitas dan kuantitas pelayanan menyebabkan kepuasan yang dirasakan oleh wajib pajak sehingga wajib pajak akan patuh dalam melaksanakan kewajibannya membayar pajak. Wajib pajak cenderung enggan menyelesaikan tanggungan pajaknya disebabkan oleh pelayanan fiskus yang dinilai kurang baik dan tanggap saat menghadapi berbagai pertanyaan atau keluhan dari wajib pajak. (Parasuraman \& Grewal, 2000) yang dikutip dalam (Nuroctaviani \& N., 2012) mengemukakan terdapat lima dimensi kualitas jasa yang dapat digunakan sebagai indikator untuk mengukur kualitas pelayanan fiskus, diantaranya: keandalan, kepastian/jaminan, cepat tanggap, empati, berwujud.

Pemenuhan kewajiban perpajakan dipacu oleh kepatuhan wajib pajak agar dapat memberikan kontribusi untuk negara yang diharapkan diberikan secara sukarela (Magee et al., 2017). Dalam penelitian yang dilakukan menyatakan SPT induk secara manual melalui Aplikasi (ASP) merupakan kelemahan E-Filling harus dikirimkan oleh wajib pajak yang menggunakan EFilling untuk melaporkan SPT. Penerapan E-Filling sangat berpengaruh secara signifikan terhadap kepatuhan perpajakan (Agustiningsih, 2016). Pernyataan tersebut sama berbeda dengan kesimpulan dari Upa, Tjahjono, \& Sesa, (2015) bahwa penerapan sistem E-Filling berpengaruh dalam menyampaikan SPT Tahunan bagi wajib pajak. 
Tabel 1. Tingkat Kepatuhan Pelaporan WPOP di KPP Pratama Badung SelatanTahun 2014-2018

\begin{tabular}{lccccc}
\hline No. & Tahun & $\begin{array}{c}\text { WPOP } \\
\text { Terdaftar }\end{array}$ & $\begin{array}{c}\text { WPOP } \\
\text { Efektif }\end{array}$ & $\begin{array}{c}\text { WPOP yang } \\
\text { Menyampaikan SPT }\end{array}$ & $\begin{array}{c}\text { Kepatuhan } \\
\text { Pajak \% }\end{array}$ \\
\hline 1. & 2014 & 58.148 & 42.026 & 20.835 & 35,83 \\
2. & 2015 & 54.521 & 33.978 & 17.054 & 50,20 \\
3. & 2016 & 57.979 & 37.422 & 14.637 & 39,11 \\
4. & 2017 & 61.915 & 41.337 & 17.281 & 41,81 \\
5. & 2018 & 59.630 & 45.326 & 23.116 & 49,90 \\
\hline
\end{tabular}

Sumber: Data Penelitian, 2019

Pada Tabel 1. terjadi fluktuasi. Disimpulkan bahwa, WPOP yang terdaftar di KKP Pratama Badung Selatan yang patuh pelaporannya dalam lima tahun terakhir berada pada persentase berkisar $30 \%$ hingga $50 \%$ yang menyatakan bahwa tingkat kepatuhan pelaporan WPOP masih rendah.

Theory of Planned Behavior menjelaskan bahwa perilaku yang ditentukan oleh individu akan timbul karena adanya minat untuk berperilaku. Theory of Planned Behavior (TPB) didasarkan pada asumsi bahwa suatu individu biasanya akan bertingkah laku sesuai dengan pertimbangan akal sehat, bahwa seseorang akan mengambil informasi yang ada mengenai tingkah laku yang tersedia secara implisit atau eksplisit dengan mempertimbangkan akibat dari tingkah laku tersebut. Perilaku yang ditunjukkan oleh seseorang juga akan mempengaruhi perilaku orang lain. Tingkat tindakan yang diharapkan seseorang akan mengarahkan orang tersebut untuk memahami tren (Mirsadeghi, 2013). Theory of Planned Behavior dalam penelitian ini secara implisit dapat mempengaruhi tingkat kepatuhan wajib pajak yaitu sosialisasi perpajakan, pengetahuan perpajakan, kualitas pelayanan fiskus, dan minat penerapan E-Filling.

Menurut Franzoni, (1999) menghitung dan menganalisi pendapatan berdasarkan peraturan pajak, membayar serta melaporkan SPT tepat pada waktunya merupakan kepatuhan wajib pajak. Seluruh studi teoritis menyimpulkan bahwa denda tarif pajak akan berdampak negatif pada pendapatan yang tidak dilaporkan (Pommerehne, 1996). Pengetahuan dapat diartikan sebagai suatu informasi yang diketahui oleh seseorang secara sadar melalui pengalaman atau pengamatan dengan inderanya (Hunt, 2003).

Menurut penelitian Supadmi \& Akuntansi, (2009) meningkatnya kepatuhan WPOP guna terpenuhinya kewajiban perpajakan, pelayanan pajak juga perlu ditingkatkan yang dilakukan fiskus. Pajak dan sistem pajak sangat penting bagi pembangunan bangsa dan negara (Oladipupo \& Obazee, 2016). Saad, (2014) berpendapat pengetahuan perpajakan menghasilkan pengaruh positif terhadap kepatuhan WPOP. Putri, (2016) menyimpulkan bahwa E-Filling menjadi salah satu faktor yang mempengaruhi kepatuhan wajib pajak. Berikut merupakan kerangka konseptual penelitian ini yang disajikan pada Gambar 1. 


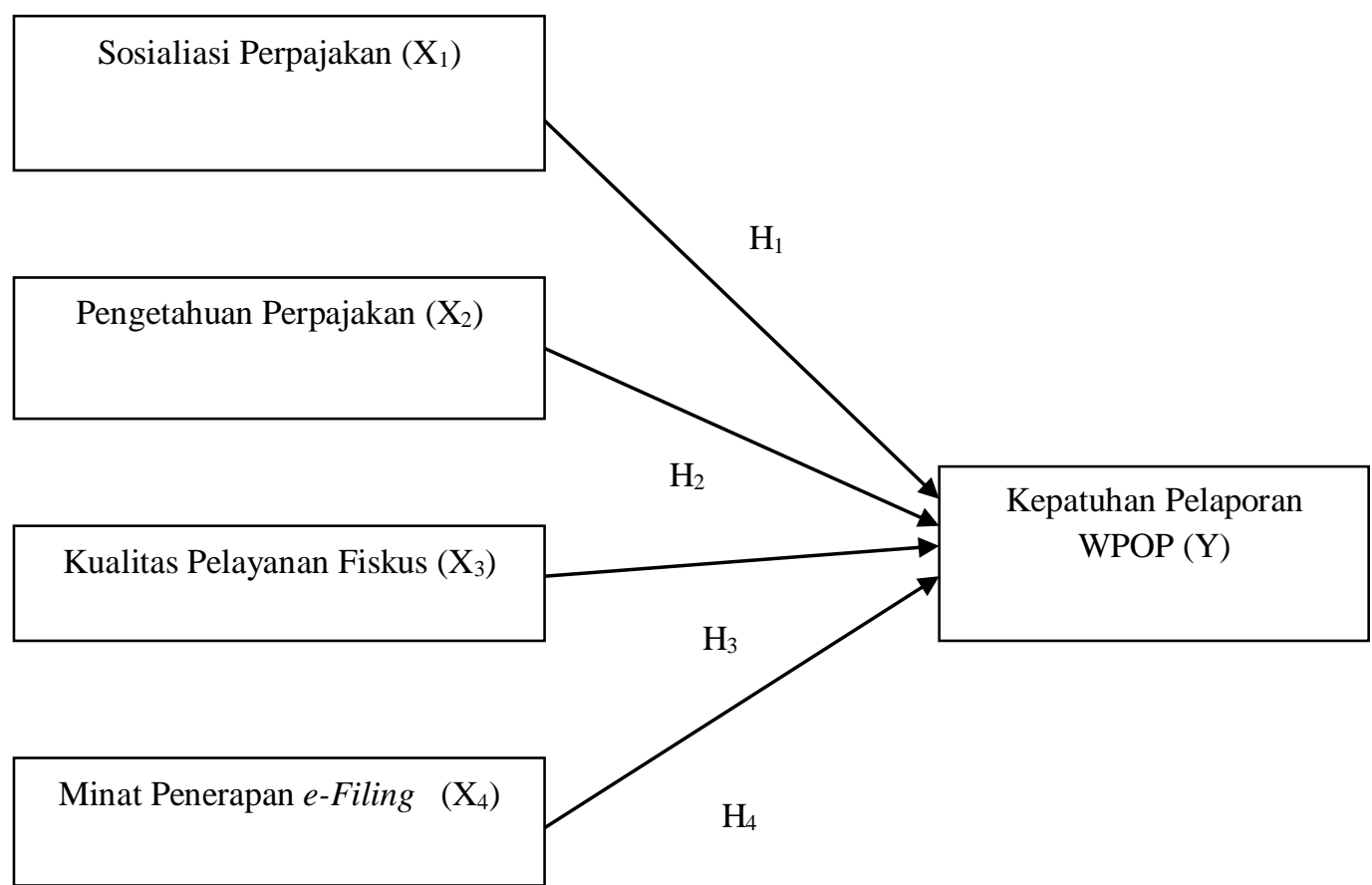

Sumber : Data Penelitian, 2019

Gambar 1. Kerangka Konseptual

\section{METODE PENELITIAN}

Pendekatan yang digunakan pada penelitian ini adalah pendekatan kuantitatif yang berbentuk asosiatif. Data kualitatif berisi gambaran umum serta tanggapan responden pada kuesioner yang diberikan. Data primer pada penelitian ini sesuai dengan responden yang telah mengisi kuesioner, sedangkan data sekunder yang digunakan adalah data-data yang diperoleh dari KPP Pratama Badung Selatan berupa tingkat kepatuhan WPOP dan jumlah WPOP yang terdaftar. Berikut merupakan persamaan regresi analisis regresi linear berganda. $\hat{Y}=\alpha+\beta 1 X 1+\beta 2 X 2+\beta 3 X 3+\beta 4 X 4+e$.

\section{HASIL DAN PEMBAHASAN}

Nilai minimum, maksimum, mean, dan simpangan baku dapat diamati hasil analisis statistik deskriptif dengan melihat besarnya.

\section{Tabel 2. Hasil Analisis Statistik Deskriptif}

\begin{tabular}{|c|c|c|c|c|c|}
\hline Variabel & $\mathrm{N}$ & Min & $\operatorname{Max}$ & Mean & Std.Deviation \\
\hline Sosialisasi Perpajakan (X1) & 100 & 7 & 15 & 12,48 & 1,7025 \\
\hline $\begin{array}{l}\text { Pengetahuan Perpajakan } \\
\text { (X2) }\end{array}$ & 100 & 7 & 16 & 12,14 & 2,0101 \\
\hline $\begin{array}{l}\text { Kualitas Pelayanan Fiskus } \\
\text { (X3) }\end{array}$ & 100 & 24 & 40 & 32,57 & 4,2646 \\
\hline $\begin{array}{l}\text { Minat Penerapan E-Filling } \\
(\mathrm{X} 4)\end{array}$ & 100 & 8 & 16 & 12.72 & 2,2744 \\
\hline $\begin{array}{l}\text { Kepatuhan Pelaporan Wajib } \\
\text { pajak orang Pribadi (Y) }\end{array}$ & 100 & 15 & 24 & 20.07 & 2,5316 \\
\hline Valid N (listwise) & 100 & & & & \\
\hline
\end{tabular}

Sumber: Data Penelitian, 2019 
Berdasarkan Tabel 2. dapat disimpulkan bahwa jumlah pengamatan (N) penelitian ini berjumlah 100. Variabel sosialisasi perpajakan memiliki nilai minimum sebesar 7 dan nilai maksimum sebesar 15 dengan nilai rata-rata sebesar 12,48 yang apabila dibagi dengan 4 item pernyataan akan menghasilkan nilai sebesar 3,12. Hal ini berarti rata-rata responden memberikan skor 3 pada setiap item pernyataan variabel sosialisasi perpajakan. Standar deviasi pada variabel ini sebesar 1,7025 yang menunjukkan bahwa standar penyimpangan data terhadap nilai rata-ratanya adalah 1,7025.

Variabel pengetahuan perpajakan memiliki nilai minimum sebesar 7 dan nilai maksimum sebesar 16 dengan nilai rata-rata sebesar 12,14 yang apabila dibagi dengan 4 item pernyataan akan menghasilkan nilai sebesar 3,03. Hal ini berarti rata-rata responden memberikan skor 3 pada setiap item pernyataan variabel pengetahuan perpajakan. Standar deviasi pada variabel ini sebesar 2,0101 yang menunjukkan bahwa standar penyimpangan data terhadap nilai rata-ratanya adalah 2,0101.

Variabel kualitas pelayanan fiskus memiliki nilai minimum sebesar 24 dan nilai maksimum sebesar 40 dengan nilai rata-rata sebesar 32,57 yang apabila dibagi dengan 10 item pernyataan akan menghasilkan nilai sebesar 3.25. Hal ini berarti rata-rata responden memberikan skor 3 pada setiap item pernyataan variabel kualitas pelayanan fiskus. Standar deviasi pada variabel ini sebesar 4,2646 yang menunjukkan bahwa standar penyimpangan data terhadap nilai rata-ratanya adalah 4,2646.

Variabel minat penerapan E-Filling memiliki nilai minimum sebesar 8 dan nilai maksimum sebesar 16 dengan nilai rata-rata sebesar 12.72 yang apabila dibagi dengan 4 item pernyataan akan menghasilkan nilai sebesar 3.18. Hal ini berarti rata-rata responden memberikan skor 3 pada setiap item pernyataan variabel minat penerapan E-Filling. Standar deviasi pada variabel ini sebesar 2,2744 yang menunjukkan bahwa standar penyimpangan data terhadap nilai rata-ratanya adalah 2,2744.

Variabel kepatuhan pelaporan wajib pajak orang pribadi memiliki nilai minimum sebesar 15 dan nilai maksimum sebesar 24 dengan nilai rata-rata sebesar 20.07 yang apabila dibagi dengan 6 item pernyataan akan menghasilkan nilai sebesar 3.34. Hal ini berarti rata-rata responden memberikan skor 3 pada setiap item pernyataan variabel kepatuhan wajib pajak orang pribadi. Standar deviasi pada variabel ini sebesar 2,5316 yang menunjukkan bahwa standar penyimpangan data terhadap nilai rata-ratanya adalah 2,5316.

Berdasarkan Tabel 3. menunjukkan bahwa instrumen penelitian yang terdiri dari item-item pernyataan sosialisasi perpajakan $\left(X_{1}\right)$, pengetahuan perpajakan $\left(X_{2}\right)$, kualitas pelayanan fiskus $\left(X_{3}\right)$, minat penerapan E-Filling $\left(X_{4}\right)$ dan kepatuhan pelaporan wajib pajak orang pribadi $(Y)$ memiliki nilai koefisien korelasi yang lebih besar dari 0,30. Jadi, seluruh indikator pernyataan tersebut telah memenuhi syarat validitas data. 
PRATIWI, P.E.M. \& JATI, I.K.

Tabel 3. Hasil Uji Validitas

\begin{tabular}{|c|c|c|c|c|}
\hline No & Variabel & $\begin{array}{l}\text { Kode } \\
\text { Instrumen }\end{array}$ & $\begin{array}{l}\text { Koefisien } \\
\text { Korelasi }\end{array}$ & Keterangan \\
\hline \multirow[t]{4}{*}{1} & \multirow[t]{4}{*}{ Sosialisasi Perpajakan $\left(\mathrm{X}_{1}\right)$} & X1.1 & 0,778 & Valid \\
\hline & & X1.2 & 0,750 & Valid \\
\hline & & X1.3 & 0,758 & Valid \\
\hline & & X1.4 & 0,717 & Valid \\
\hline \multirow[t]{4}{*}{2} & \multirow[t]{4}{*}{ Pengetahuan Perpajakan $\left(X_{2}\right)$} & X2.1 & 0,745 & Valid \\
\hline & & $X 2.2$ & 0,806 & Valid \\
\hline & & $X 2.3$ & 0,763 & Valid \\
\hline & & X2.4 & 0,650 & Valid \\
\hline \multirow[t]{10}{*}{3} & \multirow[t]{10}{*}{ Kualitas Pelayanan Fiskus $\left(\mathrm{X}_{3}\right)$} & X3.1 & 0,634 & Valid \\
\hline & & X3.2 & 0,668 & Valid \\
\hline & & X3.3 & 0,577 & Valid \\
\hline & & X3.4 & 0,448 & Valid \\
\hline & & X3.5 & 0,669 & Valid \\
\hline & & X3.6 & 0,658 & Valid \\
\hline & & X3.7 & 0,707 & Valid \\
\hline & & X3.8 & 0,789 & Valid \\
\hline & & X3.9 & 0,681 & Valid \\
\hline & & X3.10 & 0,602 & Valid \\
\hline \multirow[t]{4}{*}{4} & \multirow[t]{4}{*}{ Minat Penerapan E-Filling $\left(X_{4}\right)$} & X4.1 & 0,727 & Valid \\
\hline & & $X 4.2$ & 0,706 & Valid \\
\hline & & $X 4.3$ & 0,777 & Valid \\
\hline & & X4.4 & 0,751 & Valid \\
\hline \multirow[t]{6}{*}{5} & \multirow{6}{*}{$\begin{array}{l}\text { Kepatuhan pelaporan wajib } \\
\text { pajak orang pribadi }(Y)\end{array}$} & Y.1 & 0,723 & Valid \\
\hline & & Y.2 & 0,772 & Valid \\
\hline & & Y.3 & 0,819 & Valid \\
\hline & & Y.4 & 0,802 & Valid \\
\hline & & Y.5 & 0,719 & Valid \\
\hline & & Y.6 & 0,316 & Valid \\
\hline
\end{tabular}

Sumber: Data Penelitian, 2019

Berdasarkan Tabel 4. menunjukkan bahwa nilai Cronbach Alpha masingmasing variabel lebih besar dari 0,70. Sehingga, dapat disimpulkan bahwa pernyataan dalam kuesioner penelitian ini reliabel dan dapat digunakan.

Tabel 4. Hasil Uji Reliabilitas

\begin{tabular}{llll}
\hline No & Variabel & Cronbach's Alpha & Keterangan \\
\hline 1 & Sosialisasi Perpajakan $\left(\mathrm{X}_{1}\right)$ & 0,739 & Reliabel \\
2 & Pengetahuan Perpajakan $\left(\mathrm{X}_{2}\right)$ & 0,720 & Reliabel \\
3 & Kualitas Pelayanan Fiskus $\left(\mathrm{X}_{3}\right)$ & 0,843 & Reliabel \\
4 & Minat Penerapan E-Filling $\left(\mathrm{X}_{4}\right)$ & 0,720 & Reliabel \\
5 & Kepatuhan pelaporan wajib pajak & 0,748 & Reliabel \\
& orang pribadi $(\mathrm{Y})$ & & \\
\hline
\end{tabular}

Sumber: Data Penelitian, 2019

Berdasarkan Tabel 5. menunjukkan bahwa unstandardized residual memiliki nilai Asymp.Sig. (2-tailed) sebesar 0,614 yang lebih besar dari taraf signifikansi 0,05. Hal ini berarti seluruh data berdistribusi normal. 
Tabel 5. Hasil Uji Normalitas

\begin{tabular}{ll} 
& Unstandardized Residual \\
$N$ & 100 \\
Asymp.Sig. (2-tailed) & 0,614 \\
\hline
\end{tabular}

Sumber: Data primer diolah, 2019

Berdasarkan Tabel 6. dapat dilihat bahwa hasil uji multikolinieritas menunjukkan masing-masing variabel bebas memiliki nilai tolerance lebih besar dari 0,10 dan nilai VIF lebih kecil dari 10. Sesuai dengan hal tersebut dapat disimpulkan bahwa tidak ada multikolinieritas antar variabel bebas dalam model regresi.

Tabel 6. Hasil Uji Multikolinearitas

\begin{tabular}{llll}
\hline Variabel & \multicolumn{2}{l}{ Collinearity Statistic } & Keterangan \\
& Tolerance & VIF & \\
\hline Sosialisasi Perpajakan $(\mathrm{X} 1)$ & 0,960 & 1,042 & Bebas Multikolinearitas \\
Pengetahuan Perpajakan $\left(\mathrm{X}_{2}\right)$ & 0,951 & 1,052 & Bebas Multikolinearitas \\
Kualitas Pelayanan Fiskus $\left(\mathrm{X}_{3}\right)$ & 0,933 & 1,071 & Bebas Multikolinearitas \\
Minat Penerapan E-Filling $\left(\mathrm{X}_{4}\right)$ & 0,977 & 1.023 & Bebas Multikolinearitas \\
\hline
\end{tabular}

Sumber: Data Penelitian, 2019

Berdasarkan Tabel 7. dapat dilihat hasil uji heteroskedastisitas menunjukkan bahwa nilai signifikansi masing-masing variabel diatas 0,05 . Jadi, dapat disimpulkan bahwa model regresi dalam penelitian ini bebas dari gejala heteroskedastisitas.

Tabel 7. Hasil Uji Heteroskedastisitas

\begin{tabular}{lll}
\hline Variabel & Sig. & Keterangan \\
\hline Sosialisasi Perpajakan $\left(\mathrm{X}_{1}\right)$ & 0,682 & Bebas Heteroskedastisitas \\
Pengetahuan Perpajakan $\left(\mathrm{X}_{2}\right)$ & 0,195 & Bebas Heteroskedastisitas \\
Kualitas Pelayanan Fiskus $\left(\mathrm{X}_{3}\right)$ & 0,814 & Bebas Heteroskedastisitas \\
Minat Penerapan E-Filling $\left(\mathrm{X}_{4}\right)$ & 0,644 & Bebas Heteroskedastisitas \\
\hline
\end{tabular}

Sumber: Data Penelitian, 2019

Adapun interpretasi dari persamaan regresi tersebut adalah sebagai yaitu nilai konstanta sebesar 3.459 mengandung arti jika variabel sosialisasi perpajakan $\left(X_{1}\right)$, pengetahuan perpajakan $\left(X_{2}\right)$, kualitas pelayanan fiskus $\left(X_{3}\right)$, dan minat penerapan E-Filling $\left(\mathrm{X}_{4}\right)$ dianggap konstan pada angka 0 (nol), maka kepatuhan pelaporan wajib pajak orang pribadi $(Y)$ dapat diartikan sebesar 3,459 satuan.

Tabel 8. Hasil Uji Analisis Regresi Linear Berganda

\begin{tabular}{|c|c|c|c|c|c|}
\hline \multirow[t]{2}{*}{ Variabel } & \multicolumn{2}{|c|}{$\begin{array}{l}\text { Unstandardized } \\
\text { Coefficient }\end{array}$} & \multirow{2}{*}{$\begin{array}{l}\text { Standardized } \\
\text { Coefficient } \\
\text { Beta }\end{array}$} & \multirow[t]{2}{*}{$T$} & \multirow[t]{2}{*}{ Sig. } \\
\hline & $B$ & Std. Error & & & \\
\hline (Constant) & 3,459 & 2.841 & & 1.218 & 0,226 \\
\hline Sosialisasi Perpajakan $\left(X_{1}\right)$ & 0,417 & 0,132 & 0,281 & 3,152 & 0,002 \\
\hline Pengetahuan Perpajakan $\left(X_{2}\right)$ & 0,329 & 0,113 & 0,261 & 2,919 & 0,004 \\
\hline $\begin{array}{l}\text { Kualitas Pelayanan Fiskus } \\
\left(\mathrm{X}_{3}\right)\end{array}$ & 0,117 & 0,054 & 0,197 & 2,179 & 0,032 \\
\hline $\begin{array}{l}\text { Minat Penerapan E-Filling } \\
\left(\mathrm{X}_{4}\right)\end{array}$ & 0,283 & 0,098 & 0,255 & 2,885 & 0,005 \\
\hline Adjusted $\mathrm{R}^{2}$ & & & & & 0,247 \\
\hline$F$ & & & & & 9,098 \\
\hline Sig. F & & & & & 0,000 \\
\hline
\end{tabular}


Berdasarkan Tabel 8. maka hasil uji regresi linear berganda, maka diperoleh persamaan sebagai berikut:

$$
\hat{Y}=3.459+0,417\left(X_{1}\right)+0,329\left(X_{2}\right)+0,117\left(X_{3}\right)+0,283\left(X_{4}\right)+e
$$

Nilai koefisien regresi $\beta_{1}=0,417$ berarti apabila variabel sosialisasi perpajakan $\left(X_{1}\right)$ meningkat 1 satuan, maka persepsi kepatuhan pelaporan wajib pajak orang pribadi (Y) akan meningkat sebesar 0,417 dengan asumsi variabel lain dianggap konstan. Nilai koefisien regresi $\beta_{2}=0,329$ berarti apabila variabel pengetahuan perpajakan $\left(\mathrm{X}_{2}\right)$ meningkat 1 satuan, maka persepsi kepatuhan pelaporan wajib pajak orang pribadi (Y) akan meningkat sebesar 0,329 dengan asumsi variabel lain dianggap konstan. Nilai koefisien regresi $\beta_{3}=0,117$ berarti apabila variabel kualitas pelayanan fiskus $\left(X_{3}\right)$ meningkat 1 satuan, maka persepsi kepatuhan pelaporan wajib pajak orang pribadi (Y) akan meningkat sebesar 0,117 dengan asumsi variabel lain dianggap konstan. Nilai koefisien regresi $\beta_{4}=0,283$ berarti apabila variabel minat penerapan E-Filling $\left(X_{4}\right)$ meningkat 1 satuan, maka persepsi kepatuhan pelaporan wajib pajak orang pribadi (Y) akan meningkat sebesar 0,283 dengan asumsi variabel lain dianggap konstan.

Berdasarkan tingkat signifikansi variabel sosialisasi perpajakan sebesar 0,002 yang lebih kecil dari $a=0,05$. Hal ini menunjukkan hipotesis pertama dalam penelitian ini diterima yaitu, sosialisasi perpajakan berpengaruh positif pada kepatuhan pelaporan wajib pajak orang pribadi di Kantor Pelayanan Pajak Pratama Badung Selatan.

Berdasarkan Theory of Planned Behavior sosialisasi perpajakan merupakan suatu tindakan atau tingkah laku seseorang yang dapat mempengaruhi individu dalam melaksanakan kewajiban perpajakannya. Sosialisasi yang diberikan kepada wajib pajak dimaksudkan untuk memberikan pengertian kepada wajib pajak akan pentingnya membayar pajak. Wajib pajak menjadi mengerti dan paham tentang manfaat membayar pajak serta sanksi jika tidak membayar pajak, sehingga sosialisasi perpajakan ini dapat berpengaruh untuk menambah jumlah wajib pajak dan dapat menimbulkan kepatuhan dari wajib pajak.

Berdasarkan frekuensi jawaban responden yang diperoleh dari kuesioner pada variabel sosialisasi perpajakan, pernyataan nomor 4 meraih skor tertinggi sebesar 316. Sosialisasi menurut Theory of Planned Behavior merupakan penyebab implisit yang dapat mempengaruhi perilaku wajib pajak dalam melaksanakan kewajiban perpajakannya. Jika wajib pajak memiliki keyakinan mengenai akibat yang akan diperoleh dari melaksanakan kewajiban perpajakan, maka akan meningkatkan kesadaran wajib pajak untuk melaporkan pajak. Adanya sosialisasi perpajakan serta diberikannya pengetahuan mengenai sanksi perpajakan, akan berdampak pada meningkatnya kepatuhan wajib pajak.

Nilai signifikansi $t$ untuk varibel pengetahuan perpajakan sebesar 0,004 yang lebih kecil dari $a=0,05$. Hal ini menunjukkan hipotesis kedua dalam penelitian ini diterima yaitu, pengetahuan perpajakan berpengaruh positif pada kepatuhan pelaporan wajib pajak orang pribadi di Kantor Pelayanan Pajak Pratama Badung Selatan.

Berdasarkan Theory of Planned Behavior, pengetahuan perpajakan merupakan informasi yang dapat mempengaruhi perilaku orang lain untuk melakukan kewajiban perpajakannya. Jika wajib pajak dapat menerima informasi 
dari orang lain, maka semakin luas pengetahuan tentang ketentuan umum dan tata cara perpajakan yang dapat dipahami oleh wajib pajak, dimana hal tersebut akan berdampak pada meningkatnya kepatuhan wajib pajak. Pengetahuan perpajakan yang dimaksud ialah wajib pajak memahami betul ketentuan umum dan tata cara perpajakan yang berlaku di Indonesia dan mampu mengaplikasikan pengetahuan tersebut dalam melaksanakan kewajiban perpajakan.

Berdasarkan frekuensi jawaban responden yang diperoleh dari kuesioner pada variabel pengetahuan perpajakan, pernyataan nomor 4 meraih skor tertinggi sebesar 320. Hal tersebut mengindikasikan bahwa wajib pajak telah menggunakan pengetahuan perpajakan yang dimiliki dengan cara melaksanakan kewajiban perpajakannya untuk mengoptimalkan penerimaan negara, yang nantinya dapat menunjang pembangunan nasional yang adil dan merata.

Pengetahuan pajak mengacu pada proses, dimana pembayar pajak menjadi sadar akan undang-undang pajak dan informasi terkait pajak lainnya. Pengetahuan perpajakan berpengaruh terhadap kepatuhan wajib pajak.

Berdasarkan Tabel 8. nilai signifikansi t untuk variabel kualitas pelayanan fiskus sebesar 0,032 yang lebih kecil dari $\alpha=0,05$. Hal ini menunjukkan hipotesis ketiga dalam penelitian ini diterima yaitu, variabel kualitas pelayanan fiskus berpengaruh positif pada kepatuhan pelaporan wajib pajak orang pribadi di Kantor Pelayanan Pajak Pratama Badung Selatan.

Berdasarkan Theory of Planned Behavior, kualitas pelayanan fiskus merupakan tingkah laku yang dapat mempengaruhi perilaku orang lain untuk melakukan kewajiban perpajakannya. Jika wajib pajak dapat menerima perilaku dan tindakan dari fiskus, maka akan menimbulkan dampak positif yaitu kerelaan dari wajib pajak dalam melaksanakan kewajibannya perpajakannya.

Pelayanan fiskus dapat diartikan sebagai cara petugas pajak dalam membantu mengurus atau menyiapkan segala keperluan yang dibutuhkan wajib pajak. Kualitas pelayanan yang baik dapat diukur dari kemampuan fiskus yang cakap dalam menindaklanjuti pengaduan wajib pajak, cepat tanggap dan andal dalam menyelesaikan persoalan yang dihadapi wajib pajak, dan memiliki rasa empati yang tinggi. Pelayanan fiskus yang baik serta ditunjang dengan ketersediaan fasilitas fisik di kantor pajak merupakan hal yang penting dan bisa menjadi modal utama untuk dapat menarik perhatian dan menimbulkan kepercayaan dari wajib wajib pajak dalam melaksanakan kewajiban perpajakannya, yang berdampak pada meningkatnya kepatuhan wajib pajak.

Berdasarkan frekuensi jawaban responden yang diperoleh dari kuesioner pada variabel kualitas pelayanan fiskus, pernyataan nomor 5 meraih skor tertinggi sebesar 336. Hal tersebut mengindikasikan bahwa kualitas pelayanan fiskus di Kantor Pelayanan Pajak Pratama Badung Selatan dikatakan baik sesuai dengan visinya, "Menjadi Kantor Pelayanan Pajak Terbaik dengan sumber daya manusia yang berkualitas dan professional".

Pelayanan baik yang diberikan oleh fiskus secara langsung akan berdampak pada meningkatnya kepatuhan wajib pajak. Wajib pajak secara konsisten akan meningkatkan kepatuhannya bila didukung dengan pelayanan yang baik oleh aparat perpajakan. 
Berdasarkan Tabel 8. nilai signifikansi t untuk variabel kualitas pelayanan fiskus sebesar 0,005 yang lebih kecil dari $\alpha=0,05$. Hal ini menunjukkan hipotesis ketiga dalam penelitian ini diterima yaitu, variabel minat penerapan E-Filling berpengaruh positif pada kepatuhan pelaporan wajib pajak orang pribadi di Kantor Pelayanan Pajak Pratama Badung Selatan.

Berdasarkan Theory of Planned Behavior, minat penerapan E-Filling merupakan tingkah laku yang dapat mempengaruhi perilaku orang lain untuk melakukan kewajiban perpajakannya. Jika wajib pajak memiliki keyakinan untuk menggunakan E-Filling, maka semakin mudah wajib pajak untuk memahami dan mampu menerapkan E-Filling, dimana hal tersebut akan berdampak pada meningkatnya kepatuhan wajib pajak.

Berdasarkan frekuensi jawaban responden yang diperoleh dari kuesioner pada variable minat penerapan E-Filling, pernyataan nomor 2 meraih skor tertinggi sebesar 324. Hal tersebut mengindikasikan bahwa minat penerapan EFilling di Kantor Pelayanan Pajak Pratama Badung Selatan dikatakan baik karena wajib pajak memiliki minat yang tinggi untuk menggunakan E-Filling

Semakin baik minat penerapan E-Filling maka kepatuhan wajib pajak juga akan semakin baik, ini dikarenakan wajib pajak dalam menggunakan sistem E-Filling menganggap bahwa sistem E-Filling bermanfaat dan memudahkannya dalam melaksanakan kewajiban perpajakan, sehingga wajib pajak merasa puas menggunakan sistem E-Filling dan menyebabkan wajib pajak semakin patuh yang mengakibatkan tingkat kepatuhan semakin tinggi.

\section{SIMPULAN}

Penelitian ini berlangsung di KPP Pratama Badung Selatan mengenai kepatuhan pelaporan WPOP, maka dapat disimpulkan bahwa sosialisasi perpajakan memberikan pengaruh positif pada kepatuhan WPOP. Adanya sosialisasi perpajakan dapat memberikan informasi dan pengetahuan bagi wajib pajak, sehingga akan berdampak pada meningkatnya kepatuhan pelaporan wajib pajak. Pengetahuan perpajakan memberikan pengaruh positif pada kepatuhan WPOP. Semakin baik tingkat pemahaman atas peraturan perpajakan yang dimiliki oleh wajib pajakakan mendorong wajib pajak dalam memenuhi kewajiban perpajakannya, sehingga kepatuhan wajib juga meningkat. Kualitas pelayanan fiskus juga memiliki pengaruh positif dalam peningkatan kepatuhan WPOP. Semakin baik tingkat pelayanan yang diberikan oleh fiskus, maka kepatuhan wajib pajak juga meningkat. Minat penerapan E-Filling memberikan pengaruh positif pada kepatuhan WPOP. Semakin tinggi minat untuk menerapkan EFilling, maka akan mempermudah wajib pajak melakukan pelaporan SPT sehingga kepatuhan pelaporan wajib pajakjuga meningkat.

\section{REFERENSI}

Agustiningsih, W. (2016). Pengaruh Penerapan E-Filing, Tingkat Pemahaman Perpajakan Dan Kesadaran Wajib Pajak Terhadap Kepatuhan Wajib Pajak Di Kpp Pratama Yogyakarta. Nominal, 5(4).

Alabede, J. O., Bt. Zainol Ariffin, Z., \& Idris, K. M. (2011). Public Governance Quality and Tax Compliance Behavior in Nigeria: The Moderating Role of Financial Condition and Risk Preference. Issues In Social And Environmental 
Accounting, 5(1), 3. https://doi.org/10.22164/isea.v5i1.54

Dessy, Windarti, A., \& Nourwahida, C. D. (2017). Analisis Faktor-Faktor Yang Mempengaruhi Kepatuhan Wajib Pajak Orang Pribadi (Studi Kasus di KPP Pratama Kalideres ). Prosiding, 256-269.

Franzoni, L. A. (1999). Tax Evasion and Tax Compliance., 52-94.

Gregory. (1997). Knowledge in perception and illusion. Departemen of Psychology, Universitas of Bristol, 352, 1121-1128.

Hammouri, Q., \& Abu-Shanab, E. (2017). Exploring the factors influencing employees' satisfaction toward e-tax systems. International Journal of Public Sector Performance Management, 3(2), 169-190. https:// doi.org/10.1504/IJPSPM.2017.084673

Hasseldine, J. (2014). International Studies Program Working Paper 10-21 May 2010 The Administration of Tax Systems John Hasseldine. (January 2010).

Hunt, D. P. (2003). The concept of knowledge and how to measure it. Journal of Intellectual Capital, 4(1), 100-113. https:/ / doi.org/10.1108/14691930310455414

Kamleitner, B., Korunka, C., \& Kirchler, E. (2012). Tax compliance of small business owners: A review. International Journal of Entrepreneurial Behaviour and Research, 18(3), 330-351. https:/ / doi.org/10.1108/13552551211227710

Kasipillai, J., \& Jabbar, H. A. (2006). Gender and Ethnicity Differences in Tax Compliance. Asian Academy of Management Journal, 11(2), 73-88.

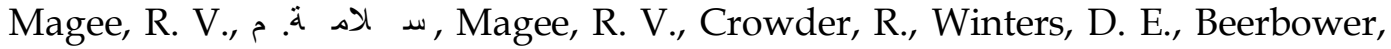
E., ... Gorski, P. C. (2017). Exploring The Factors Influencing Eemployees Satisfaction Toward E-Tax Systems. ABA Journal, 102(4), 24-25. https:// doi.org/10.1002/ejsp.2570

Mahardika, I. G. N. P. (2015). Pengaruh Kualitas Pelayanan Dan Sikap Wajib Pajak Pribadi Di Kpp Pratama Singaraja. Jurnal Jurusan Pendidikan Ekonomi (JJPE), 5(1), 1-12.

Mirsadeghi, S. (2013). A Review on the Attribution Theory in the Social Psychology. IOSR Journal of Humanities and Social Science, 8(6), 74-76. https:// doi.org/10.9790/0837-0867476

Nuroctaviani, Y. R., \& N., Y. A. B. B. (2012). Pengaruh Kualitas Layanan terhadap Kepatuhan Membayar Wajib Pajak (Studi Kasus di Kantor Pelayanan Pajak di Jakarta Kelapa Gading). Jurnal Informasi, Perpajakan, Akuntansi Dan Keuangan Publik, 7(1), 61-72.

Oladipupo, A. O., \& Obazee, U. (2016). Tax Knowledge, Penalties and Tax Compliance in Small and Medium Scale Enterprises in Nigeria. IBusiness, 08(01), 1-9. https://doi.org/10.4236/ib.2016.81001

Parasuraman, A., \& Grewal, D. (2000). Serving customers and consumers effectively in the twenty-first century: A conceptual framework and overview. Journal of the Academy of Marketing Science, 28(1), 9-16. https:// doi.org/10.1177/0092070300281001

Pommerehne, W. W. (1996). Tax rates, tax administration and income tax evasion in Switzerland. Public Choice, 88(1-2), 161-170. https:// doi.org/10.1007/BF00130416

Putri. (2016). Faktor-Faktor Yang Mempengaruhi Kepatuhan Penyampaian Surat Pemberitahuan (Spt) Tahunan Wajib Pajak Orang Pribadi (OP) (Studi pada 
Wajib Pajak Orang Pribadi di KPP Pratama Kepanjen). Jurnal Ilmiah Akuntansi Dan Bisnis.

Saad, N. (2014). Tax Knowledge, Tax Complexity and Tax Compliance: Taxpayers' View. Procedia - Social and Behavioral Sciences, 109(1), 1069-1075. https:// doi.org/10.1016/j.sbspro.2013.12.590

Santoso, S. N. (2015). Pengaruh Pengetahuan Pajak, Kesadaran Wajib Pajak, Dan Sanksi Pajak Terhadap Kepatuhan Wajib Pajak (Studi Pada Wajib Pajak Orang Pribadi Di Kantor Pelayanan Pajak Kepanjen). Jurnal Mahasiswa Perpajakan, 6(1).

Sentanu, I., \& Setiawan, P. (2016). Pengaruh Kualitas Pelayanan, Kewajiban Moral Dan Sanksi Perpajakan Pada Kepatuhan Wajib Pajak Hotel. E-Jurnal Akuntansi, 16(1), 306-332.

Supadmi, N. I. L. U. H., \& Akuntansi, J. (2009). Meningkatkan Kepatuhan Wajib Pajak Melalui Kualitas Pelayanan. Jurnal Ilmiah Akuntansi Dan Bisnis, 1-14.

Upa, V. A., Tjahjono, J. K., \& Sesa, E. S. (2015). Pengaruh Presepsi Wajib Pajak Orang Pribadi Pada Penerapan e-Filing Terhadap Tahunan Di Kota Surabaya (Vol. 4). 